I recommend it to all marketers who are serious about planning and buying media in today's complex and fast-changing marketing landscape.

Mike Berry Dip DM, F IDM

\section{Speaking from experience}

Its central point of view: if you would get your message through, you need to adopt a carefully structured 'campaign' approach to the business of communicating
I like to know who's talking to me. And, frankly, I'm wary of anyone claiming to be a martial artist and even more of anyone who willingly admits playing a big part in getting Bill Clinton and Tony Blair elected. So, from the start of this book, I had reservations about both its authors. But the former suggests a dedication to rigour and discipline and the latter some knowledge of and success at campaigning, so I decided to give the pair the benefit of the doubt. As it happens, I found they write well, clearly and have useful things to say on a subject of massive importance.

Information is getting out. Communication is getting through. For fundraisers and direct marketers, the difference is crucial. This is an easy, accessible book and just the ticket for anyone looking for a primer on campaigning via communications. And that's its central point of view. If you would get your message through, you need to adopt a carefully structured 'campaign' approach to the business of communicating. The 'campaign it' model is described in detail, but essentially is an attitude of mind supported by a set of skills and a process. The authors keep coming back to their model throughout the book, telling you step by step how to campaign your communications and supporting their arguments with numerous case histories and practical insights. It's a sound argument: You could do worse than employ their philosophy to underpin your communications.

Instructive examples are sprinkled liberally throughout the text as are good and sometimes not so good quotes. I like Fanny Brice saying, 'Your audience gives you all you need. They tell you. There is no director like your audience'. On the same page though Frank Lloyd Wright is quoted saying, 'Get the habit of analysis. Analysis will in time enable synthesis to become your habit of mind'.

I mean, imagine saying something like that, out loud ....

We are told 'campaigners need to be courageous as well as ethical', and 'objectives are those things you have to achieve to realize your cause'. This seems obvious! But fair enough, this is a beginners' guide 


We don't sufficiently
elevate the art
and science of
communication in
our strategies nor
do we value or
even understand
communication skills
and invest anything
like what we should
in ensuring that our
communicators are well
equipped with them

We don't sufficiently elevate the art and science of communication in our strategies nor do we value or even understand communication skils and invest anything like what we should communicators are well equipped with them and these things should be said somewhere, probably often. Where better than a 'how-to' book on campaigning?

It is careless in places too, eg Page 16, where it cites the cost of employee misunderstandings (through bad communications) in the United Kingdom and the United States as $£ 31$ million (US\$62 million). No, not even if the dollars were Australian or Canadian, as even with them it's been a while since we got two for one. For US dollars, it would be more like $\$ 48$ million. But the point is well made. Poor communications badly campaigned costs shedloads, in any currency.

And this is nit-picking. Most of this book is plain nuts and bolts, no high ground is taken. Except for its constant reiteration of the basic observation that, for our causes, we need and deserve to be heard. And we can be, if only we do it properly.

The important thing, which this book articulates well, is that most of the organizations we work with do information by the binlorryload, at vast expense, but often border on useless at communication. They get stuff out, but don't get it through. Paradoxically, we don't sufficiently elevate the art and science of communication in our strategies nor do we value or even understand communication skills and invest anything like what we should in ensuring that our communicators are well equipped with them.

Campaign it!: Achieving success through communication gives you a very good starting point to putting this paradox right. I recommend that you buy several copies, distribute them among your most talented folks then tell them you'll be asking questions soon and that jobs will hinge on it. But keep one copy back for yourself, so that you'll know at least as much about the campaign approach to communication as they do.

You won't regret it. And your job will be safe.

Ken Burnett Hon F IDM

\section{Digital wars: Apple, Google, Microsoft and the battle for the internet}

Charles Arthur

Kogan Page, 2012; £14.99; 272pp.

ISBN: 978-0749464134 (Paperback)

Journal of Direct, Data and Digital Marketing Practice (2012) 14, 84-86. doi:10.1057/dddmp.2012.21

Charles Arthur has been the technology editor for The Guardian since 2005, and his 'Digital Wars' is a highly readable account of the evolution since 1990 of that part of the technology industry that focuses on consumer products involving search, digital music, smartphones and tablets. This evolution is given dramatic context by being framed within an account of a series of battles between the protagonists competing to control access by consumers to digital information and services. 